\title{
IMPLEMENTING PRACTICAL BASED COURSES UNDER OPEN AND DISTANCE LEARNING SYSTEM: A STUDY OF THE PERCEPTION OF LEARNERS AND COUNSELLORS
}

\author{
Dr. Tapan Kumar BASANTIA \\ School of Education \\ Central University of South Bihar \\ Gaya, India
}

\section{ABSTRACT}

Implementing practical based courses under Open and Distance Learning (ODL) system is a very difficult and challenging task as the teaching of practical based courses involves intensive practical work. For removing the difficulties and challenges in implementing the practical based courses under ODL system, there is a need to study the existing status and problems found in the way of implementing practical based courses under ODL system. The learners and counsellors of practical based courses under ODL system are the practical stake holders of ODL system who can judiciously perceive and identify the existing status and problems in implementing practical based courses under ODL system. But, from the literature of research in the field of ODL system, it is found that hardly study has been carried out to study the perception of learners and counsellors in implementing practical based courses under ODL system. Therefore, the present study has attempted to study the perception of learners and counsellors in implementing practical based courses under ODL system. The study intended to achieve two objectives: (i) to study the perception of the learners in implementing practical based courses under open and distance learning system, and (ii) to study the perception of the counsellors in implementing practical based courses under open and distance learning system. The study is considered under descriptive survey type research. Twenty learners who were pursuing the Bachelor of Science (B. Sc.) course and twenty counsellors who were counselling B.Sc. learners in two selected study centers of Indira Gandhi National Open University(IGNOU) Regional Center, Bhubaneswar (i.e. IGNOU Study Center, B.J.B. College, Bhubaneswar and IGNOU Study Center, Khalikote College, Berhampur) were taken as participants for the study. Purposive sampling method was followed for selecting the participants for the study. Data were collected personally from the participants in a natural and comfortable setting. Two tools (i.e. Perception scale for studying the perception of the learners in implementing practical based courses under open and distance learning system; and Perception scale for studying the perception of the counsellors in implementing practical based courses under open and distance learning system) were used for collection of data from the participants of the study. A mix of qualitative and quantitative methods/approaches of data analysis was used for analyzing the data of the study. The results of the study mainly highlighted the perception of the learners and counsellors regarding existing status and problems in implementing practical based courses under ODL system and their suggestions in implementing practical based courses under open and distance learning system.

Keywords: Practical based courses, open and distance learning, learner, counsellor.

\section{INTRODUCTION}

Open and distance learning (ODL) is now being accepted worldwide as an alternative teaching-learning and training medium. It is quite popular for teaching courses in humanities and social sciences. Slowly, for the teaching sciences and the other practical based courses, the open and distance learning system is gaining the importance. The Indian 
distance education scene is a complex and multifaceted one. In recent years a number of institutions in India have started devoting attention to practical based programs along with theory based programs through open and distance learning mode. The Dr. B. R. Ambedkar Open University (BRAOU), Hyderabad, has the distinction of being the first to make available Bachelor's level programs in the Science subjects and a certificate program in Food and Nutrition. BRAOU started offering science education in the year 1983. The Yashwantrao Chavan Maharashtra Open University (YCMOU), Maharashtra offers Certificate and Diploma level programs in Computers, Electronics and Agriculture, etc. (Damayanti, 1996). IGNOU has introduced more than 125 academic programs and around 1000 courses in a variety of disciplines like Computer, Management, Engineering, Science and Technology, Health Sciences, Agriculture, Social Sciences including Tourism and Library Sciences, Humanities including Journalism and Creative Writing, etc.(Srivastava,2006).

There exists some differences between theory based courses and practical based courses under ODL system. In case of the theory based courses, learners have to closely be associated with the study centers. Study materials are provided to them and they have to submit assignments within a stipulated time. Personal-Contact Programs (PCP) and multimedia facilities are also provided to the learners, and at the end of each term, the institutions conduct term-end examinations. The learners have to attend term-end examinations within a stipulated time. But, in case of practical based programs, apart from the theory part of the courses, the learners have to conduct practical in the designated laboratories. Attendances in practical sessions are compulsory for the completion of the courses.

The emergence and the use of information and communication technology (ICT) made open and distance learning mode effective in delivering courses in disciplines which need intensive practical and face to face situations. In spite of the potentialities of the media and self-learning nature of the instructional/training modules, many obstacles have been encountered in teaching practical base courses like courses in Science and Technology, Agriculture, Nursing, Medicine, Vocational Training and so on (Nigam and Joshi, 2007). Several Indian institutes of higher learning are offering practical based courses at Bachelor's, Certificate and Diploma levels through distance mode. The print medium is still the primary substitute of the teacher in both the theory and practical based courses. The printed self-instructional learning materials are supplied to the learners for both theory and practice. Besides this, the institutes conduct contact-cum-counseling session for the theory based courses, for which attendance is not compulsory. However, for the practical based courses, practical contact sessions and assignments are crucial components, the evaluation of which is handled at the level of study centers. Writing assignment and attending practical sessions are compulsory for the learners of practical programs (Agarwal, et al., 2007). Generally, infrastructure and facilities for laboratory experiments are not practically up-to-date and adequate even in conventional institutions in the developing countries. Obviously, hands-on experience is essential for effective transfer to students of technical skills which are often limited in distance education (Jung and Latchem, 2007). For the open and distance learning environment, the teaching of practical skills poses considerably more difficulties than the teaching of knowledge and theory (Hampton, 2002). Khare et al. (2004) conducted a study and viewed that only $37 \%$ of the students admitted to IGNOU's B.Sc. program are active and only one fourth of them attempted to lab courses. Soni (2008) has mentioned that, distance teaching directorates, which offer courses in science and technology, confront the problem of providing laboratory facilities to the students. Koul (2005) stated that though the practical sessions were found to be useful, adequately timed and relevant to the work area but the number of practical sessions was found to be inadequate. Effective monitoring is the most significant means of ensuring quality standards in any given situation. But, it is seen that there exists some specific problems in the monitoring of the conduct of laboratory courses in the study centers. Lack of laboratories at regional centers, lack of infrastructure facilities, lack of laboratory equipments, lack of trained manpower and financial constraints, etc. adversely affect the learning process and performance of the learners. 
The importance of practical based courses under open and distance learning system is rising rapidly. Like traditional system of education, open and distance learning system is also introducing practical based courses along with theory based courses. Number of open learning institutions has increased quantitatively as well as qualitatively and they are offering various types and levels of practical based courses. There is still need for opening more number of practical based courses and also at different levels. The study conducted by Nigam and Joshi (2007) indicates that promotion of science courses and programs by distance education is the need of the hour and more courses with market and industry orientation should be offered to help working people to equip and update themselves without sacrificing their job and promotional avenues. But, introducing practical based courses through ODL system is not an easy task as ODL system is a self-instructional system. In ODL system, the physical separation of teacher and the learner distinguishes it from formal education. The system of providing practical based courses is different from the theory-based courses in many ways. The teaching of practical based courses involves intensive practical work, and running of such courses in open and distance education requires special techniques, learning material and specialized learning center. Hence, opening/implementing practical based courses through ODL system is a very challenging task. Several issues may arise in this regard. Therefore, there is need to know the issues and challenges for opening and implementing practical based courses through open and distance learning mode.

The success rate of any system shows how far the system is able to attain its goals. If the success level of practical based courses under ODL system could not be improved, then it will certainly be failed in contributing meaningfully for the development of individuals and society and in turn for the country. So, a clear, thorough and systematic approach is needed for implementing practical based courses under ODL system. Since the implementation of practical based courses under ODL system faces a lot of difficulties, so, there is a danger and it may so happen that the practical based courses under ODL system may become stereotype and deteriorate until and unless such difficulties are removed. For removing the difficulties in implementing the practical based courses under ODL system, there is a need to study the existing status and problems found in the way of implementing practical based courses under ODL system. The learners and counsellors of practical based courses under ODL system are the practical stake holders of ODL system who can judiciously perceive and identify the status and problems in implementing practical based courses under open and distance learning system But, from the literature of research in the field of ODL system, it is found that hardly study has been carried out to study the perception of learners and counsellors in implementing practical based courses under ODL system. Therefore, the present study has attempted to study the perception of learners and counsellors in implementing practical based courses under ODL system.

\section{Objectives of the Study}

The study intended to achieve two objectives as given below:

$>$ To study the perception of the learners in implementing practical based courses under open and distance learning system, and

$>$ To study the perception of the counsellors in implementing practical based courses under open and distance learning system.

\section{DEFINITION OF THE CONSTRUCTS}

The study is concerned with two significant constructs i.e. 'practical based courses' and 'open and distance learning'. The definition of the constructs is given here below.

\section{Practical Based Courses}

In general, practical based courses are such courses or subjects where the practical/ action /skill related tasks like project works, experimentations etc. are found. In the present study, practical based courses are understood as the courses which are evaluated through three ways evaluation system i.e. 'term end theory examination', 'term end practical 
examination' and 'submission of assignments'. Practical based courses are functionally different from theory based courses from many fronts. Theory based courses are such courses or subjects where the practical based tasks like projects, experimentations etc. are hardly/less found.

\section{Open and Distance Learning}

In general open and distance learning refers to a system of learning in which learning is acquired in an open and/or distance mode through open learning institutions, distance learning centers of conventional institutions etc. Present study is confined to open and distance learning run by Open University/Institution.

\section{BACKGROUND OF SELECTING THE SAMPLE INSTITUTIONS}

As the study intended to study the perception of learners and counsellors in implementing practical based courses under open and distance learning system, so, the study intended to include such type of institutions as sample institutions where practical based courses are offered. Generally, the open and distance learning institutions are not much wide spread like conventional learning institutions. Further, in very less number of open and distance learning institutions, practical based courses are offered. Further, getting the sufficient number learners pursuing the practical based courses and counsellors counselling learners of practical based courses is not easy task. Taking all these contexts into considerations, the present study is delimited to such kind of open and distance learning institutions where practical based courses are offered. The study is delimited to two study centers of Indira Gandhi National Open University (IGNOU) Regional Center, Bhubaneswar, India. Along with offering large number of theory based courses, IGNOU also offers some practical based courses like Master of Computer Application (MCA), Master of Science in Dietetics and Food Service Management (M.Sc. DFSM), Bachelor of Computer Application (BCA), Bachelor of Science (B. Sc.), Bachelor of Science Honors in Optometry \& Ophthalmic Techniques (BSCHOT), etc. in its different regional centers including its Regional Center, Bhubaneswar.

The study is further delimited to B. Sc. course of IGNOU. This course is a general course (but not honors course) of IGNOU. The course is a prestigious academic course of the University. It opens up avenues of higher education in science to people from different sections of the society such as in-service personnel, housewives, weaker sections, and people living in rural and remote areas. Eligibility criteria for getting admission in to this course are $10+2$ with science or its equivalent qualification. Minimum duration of completing this course is three years and maximum duration is six years. Learners are required to complete a minimum percent attendance in theory counselling to become eligible for appearing the Term-End Examination of the course. Similarly, they are required to complete a minimum percent attendance in practical contact sessions to become eligible for appearing the practical examination of the course. Assignment is also an important component of this course.

\section{Locale of the Study}

B. Sc. course is not offered in all the regional centers and/or study centers of IGNOU, rather it is offered in its selected regional centers and/or study centers. Taking in to consideration the feasibilities for conducting the study, the two study centers of IGNOU Regional Center, Bhubaneswar (i.e. IGNOU Study Center, B.J.B College, Bhubaneswar and IGNOU Study Center, Khalikote College, Berhampur) were purposively chosen as locale of the study as in these two study centers B. Sc. course is offered. The study was conducted on twenty learners who were pursuing B. Sc. course and twenty counsellors who were counselling the B.Sc. learners in these two study centers.

\section{METHODOLOGY}

The study studied the perception of the learners and counsellors in implementing practical based courses under open and distance learning system. The study falls under descriptive 
survey type research. The study is considered under descriptive survey type research because in this study the data have been collected from learners and counsellors of the sample institutions (i.e. IGNOU study Center, B.J.B College, Bhubaneswar and IGNOU study Center, Khalikote College, Berhampur) through descriptive survey method in order to study their perception in implementing practical based courses under open and distance learning system.

\section{Participants}

Purposive sampling method was followed for selecting the participants for the present study. From the two sample institutions (i.e. IGNOU study Center, B.J.B College, Bhubaneswar and IGNOU study Center, Khalikote College, Berhampur) twenty learners who were pursuing the B. Sc. course and twenty counsellors who were counselling B.SC. learners were taken as the participants for conducting the study. The details of the description of the participants are given below.

Table 1. Description of Participants

\begin{tabular}{lllcl}
\hline $\begin{array}{c}\text { Sl. } \\
\text { No. }\end{array}$ & Name of the IGNOU Study Centers & Name of Courses & No of Learners & $\begin{array}{c}\text { No of } \\
\text { Counselors }\end{array}$ \\
\hline 1 & BJB College, Bhubaneswar & B.Sc. & 12 & 12 \\
2 & Khalikot College, Berhampur & B.Sc. & 8 & 8 \\
\hline
\end{tabular}

Tools Used

Two tools were administered on the participants. The brief nature of the tools and their administration are given below.

Tool-I (Perception Scale for Studying the Perception of the Learners in Implementing Practical Based Courses under Open and Distance Learning System)

This tool was used for achieving first objective of the study (i.e. to study the perception of the learners in implementing practical based courses under open and distance learning system). The participants of the tool were the twenty learners who were pursuing the $B$. Sc. Course. The items of the tool touch the different aspects of implementation of the practical based courses under open and distance learning system. The tool included three categories of items i.e. Category-A items, Category-B items and Category-C items. Category-A items are used to study the perception of the learners regarding existing status of implementing practical based courses; Category-B items are used to study the perception of the learners regarding existing problems of implementing practical based courses; and Category- $\mathrm{C}$ items are used to secure the suggestions of the learners regarding effective implementing of practical based courses. While the items of Category-A and Category-B of the tool require close ended responses (i.e. responses in terms of choices from fixed number of options of the items), the items of Category- $C$ of the tool require open ended responses (i.e. free responses or responses without referring any options of the items). Construct validity of the scale has been established. For establishing construct validity of the scale, at first, a set of tentative items were developed for inclusion in the scale. Such developed items were placed before the experts of distance education for securing their healthy comments and suggestions regarding the items of the scale. On basis of the comments and suggestions from experts regarding the items of the scale, the items of the scale were improved and accordingly finalized for the scale. There is no fixed time limit for administration of the scale. Further, there is no any fixed pattern of scoring of the items of the scale because the items of the scale differ among themselves in their nature. The items of the tool require both quantitative and qualitative approaches of scoring and/or interpretation.

Tool-II (Perception Scale for Studying the Perception of the Counsellors in Implementing Practical Based Courses under Open and Distance Learning System)

This tool was used for achieving second objective of the study (i.e. to study the perception of the counsellors in implementing practical based courses under open and distance learning system). The participants of the tool were the twenty counsellors who were 
counseling B.Sc. learners. The items of the tool touch the different aspects of implementation of the practical based courses under open and distance learning system. The tool included three categories of items i.e. Category-A items, Category-B items and Category-C items. Category-A items are used to study the perception of the counsellors regarding existing status of implementing practical based courses; Category-B items are used to study the perception of the counsellors regarding existing problems of implementing practical based courses; and Category-C items are used to secure the suggestions of the counsellors regarding effective implementing of practical based courses. While the items of Category-A and Category-B of the tool require close ended responses (i.e. responses in terms of choices from fixed number of options of the items), the items of Category-C of the tool require open ended responses (i.e. free responses or responses without referring any options of the items). Construct validity of the scale has been established. For establishing construct validity of the scale, at first, a set of tentative items were developed for inclusion in the scale. Such developed items were placed before the experts of distance education for securing their healthy comments and suggestions regarding the items of the scale. On basis of the comments and suggestions from experts regarding the items of the scale, the items of the scale were improved and accordingly finalized for the scale. There is no fixed time limit for administration of the scale. Further, there is no any fixed pattern of scoring of the items of the scale because the items of the scale differ among themselves in their nature. The items of the tool require both quantitative and qualitative approaches of scoring and/or interpretation.

Process of Collection of Data

Data were collected personally from the participants for conducting this study. Data were collected from the participants in a natural and comfortable setting. The data were collected from the participants when they were available in their respective study centers. The data were collected from the learners of who were enrolled in B. Sc. course in 2010 session and counsellors who were counseling the learners enrolled in 2010 in B. Sc. course in the respective study centers.

Process of Analysis of the Results

A mix of qualitative and quantitative methods/approaches of data analysis was used for analyzing the data of the study. Along with the use of quantitative method of percentage, qualitative description of results constituted important parameter for analyzing the results of the study.

\section{Analysis of the Results}

The details of the analysis of the results of the study are presented in the following heads:

Perception of the Learners in Implementing Practical Based Courses under Open and Distance Learning System

Perception of the twenty learners in implementing practical based courses under open and distance learning system is given below.

\section{Perception of the learners regarding existing status of implementing practical based courses}

$\mathbf{5 5 \%}$ learners opined that practical based courses under open and distance learning system bear inferior status in comparison to practical based courses under conventional colleges/institutes; $30 \%$ learners opined that practical based courses under open and distance learning system bear equal status with practical based courses under conventional colleges/institutes; and 15\% learners opined that practical based courses under open and distance learning system bear superior status in comparison to practical based courses under conventional colleges/institutes. $50 \%$ learners viewed that theory components are emphasized more than the practical components in practical based courses; $40 \%$ learners viewed that both theory components and practical components are equally emphasized in practical based courses; and $10 \%$ learners viewed that practical components are emphasized more than the theory components in practical based courses. $50 \%$ learners gave their view that both sessional practical and term end practical are equally emphasized 
among the practical components of practical based courses; $30 \%$ learners gave their view that sessional practical is emphasized more than the term end practical among the practical components of practical based courses; and $20 \%$ learners gave their view that term end practical is emphasized more than the sessional practical among the practical components of practical based courses.

All the learners stated that sessional practical is conducted in specific times of the session whereas no learner stated that sessional practical is conducted throughout the session. $50 \%$ learners reacted that multi-media is used to a minimal extent in practical activities; $30 \%$ learners reacted that multi-media is used to a medium extent in practical activities; and $20 \%$ learners reacted that multi-media is used to a maximum extent in practical activities. $85 \%$ learners put forth their view that $50 \%$ to $75 \%$ attendance is secured in practical sessions; and $15 \%$ learners put forth their view that $25 \%$ to $50 \%$ attendance is secured in practical sessions. $\mathbf{5 0 \%}$ learners indicated that facilities relating to practical equipment and related things are available to a considerable extent in practical laboratory/workshop; $\mathbf{4 0 \%}$ learners indicated that facilities relating to practical equipment and related things are available to a maximum extent in practical laboratory/workshop; and $10 \%$ learners indicated that facilities relating to practical equipment and related things are very less available in practical laboratory/workshop. $60 \%$ learners stated that the counsellors/tutors who guide the learners to do their practical are well trained and experienced; $30 \%$ learners stated that the counsellors/tutors who guide the learners to do their practical are moderately trained and experienced; and $10 \%$ learners stated that the counsellors/tutors who guide the learners to do their practical are less trained and experienced. $80 \%$ respondents viewed that the fees charged for pursuing practical based courses are considerable; $10 \%$ respondents viewed that the fees charged for pursuing practical based courses are minimal; and $10 \%$ respondents viewed that the fees charged for pursuing practical based courses are maximal. All the learners stated that practical works are conducted in the study center / sub-study center only whereas no learner stated that the practical works are conducted either in the regional/main center or in regional/main center and study center /sub-study center.

All the learners opined that counsellors/tutors and laboratory assistants/technicians are engaged in guiding them in their practical activities and no learner opined that special experts/resource persons are engaged in guiding them in their practical activities. Further, all the learners supported the view that rule is there concerning a minimum percentage of attendance is required in sessional practical in order to attain the term end practical and if someone will not achieve the minimum percentage of attendance in sessional practical, s/he cannot be allowed to attain the term end practical. $90 \%$ learners supported the view that all the components of the practical of their course are conducted properly and in time whereas $10 \%$ respondents did not support the view that all the components of the practical of their course are conducted properly and in time. All the learners are agreed on the point that no special practical session (other than normal practical session) is arranged for the learners who couldn't /don't attain the normal practical sessions. $70 \%$ learners supported the view that timing of the practical suits to them whereas $30 \%$ learners did not support the view that timing of the practical suits to them. All the learners agreed on the point that home based practical works are not assigned to them.

\section{Perception of the learners regarding existing problems of implementing practical based courses}

$\mathbf{5 0 \%}$ learners don't encounter any problem relating to doing practical whereas all other learners encounter problem relating to doing practical in one way or other which are cited here: $30 \%$ learners encounter problems of the adjustment of time; $25 \%$ learners fail to understand the practical classes properly; $15 \%$ learners find no residential facility in the study center; $15 \%$ learners find that practical classes are done superficially; $10 \%$ learners encounter communication problem to the study center; $10 \%$ learners find that that large number of students do practical at a time; and $5 \%$ learners face problem to understand the language used in the practical class. 
Suggestions of the learners regarding effective implementing of practical based courses $\mathbf{4 0} \%$ learners gave no suggestion for effective implementing of practical based courses under ODL system where as all other learners gave suggestion regarding effective implementing of practical based courses under ODL system in one way or other which are cited here: $25 \%$ learners suggested that timing of the practical should be designed according to the needs of the learners; $20 \%$ learners suggested that home based practical should be conducted; $15 \%$ learners suggested that the study center should have its own practical instruments and laboratory; $10 \%$ learners suggested that practical should be conducted in small groups; $5 \%$ learners suggested that practical should be conducted during the holiday time; and 5\% learners suggested that E-based practical should be encouraged.

Perception of the Counsellors in Implementing Practical Based Courses under Open and Distance Learning System

Perception of the twenty counsellors in implementing practical based courses under open and distance learning system is given below.

Perception of the counsellors regarding existing status of implementing practical based courses

$80 \%$ counsellors opined that if practical based courses would be introduced under ODL system, they would be moderately successful; $10 \%$ counselors opined that if practical based courses would be introduced under ODL system, they would be highly successful; and $10 \%$ counsellors opined that if practical based courses would be introduced under ODL system, they would be less successful. $50 \%$ counsellors viewed that delivering practical components of the practical based courses to the learners of ODL system is more difficult; $30 \%$ counsellors viewed that delivering practical components of the practical based courses to the learners of ODL system is less difficult; and $20 \%$ counsellors viewed that delivering practical components of the practical based courses to the learners of ODL system is most difficult. $\mathbf{5 0 \%}$ counsellors gave their views that existing practical based courses under ODL system are maintaining balance between theory components and practical components; $45 \%$ counsellors gave their views that existing practical based courses under ODL system are tilted more towards theory components; and $\mathbf{5 \%}$ counsellors gave the view that existing practical based courses under ODL system are tilted more towards practical components. $45 \%$ counsellors put forth their view that student involvement and progress in practical activities of practical based courses is low; $30 \%$ counsellors put forth their view that student involvement and progress in practical activities of practical based courses is high; $20 \%$ counsellors put forth their view that student involvement and progress in practical activities of practical based courses is very high; and $5 \%$ counsellors put forth the view that student involvement and progress in practical activities of practical based courses is very low. $40 \%$ counsellors indicated that practical laboratories/workshops for practical based courses under ODL system are moderately equipped with practical materials and equipment; 35\% counsellors indicated that practical laboratories/workshops for practical based courses under ODL system are adequately equipped with practical materials and equipment; and $25 \%$ counsellors indicated that practical laboratories/workshops for practical based courses under ODL system are less equipped with practical materials and equipment.

$\mathbf{5 0 \%}$ counsellors stated that long term practical based courses would be more successful under ODL system; $30 \%$ counsellors stated that short term practical based courses would be more successful under ODL system; and $20 \%$ counsellors stated that both long term practical based courses short term practical based courses would be successful under ODL system. 55\% counsellors stated that they prefer evaluation/certification system based on grading system bearing the marks for practical based courses; $25 \%$ counsellors stated that they prefer evaluation/certification system based on marking system indicating the divisions for practical based courses; and $20 \%$ counsellors stated that they prefer evaluation/certification system based on grading system without bearing marks for practical based courses. $60 \%$ counsellors viewed that there would be no difference between annual system evaluation and semester system evaluation for the evaluation 
practice for practical based courses under ODL system; $20 \%$ counsellors viewed that annual system evaluation would work better for practical based courses under ODL system; and $20 \%$ counsellors viewed that semester system evaluation would work better for practical based courses under ODL system.

All the counsellors are agreed on the point that the lab attendants/technicians are appointed to help the counsellors to guide the learners in their practical activities. $80 \%$ counsellors reacted that special experts/resources persons are not appointed to help the counsellors to guide the learners in their practical activities whereas $20 \%$ counsellors reacted that special experts/resources persons are appointed to help the counsellors to guide the learners in their practical activities. $90 \%$ counsellors supported the view that existing number of practical sessions provided by the institute/study center caters the practical related demands of the learners adequately whereas10\% counsellors did not support the view that existing number of practical sessions provided by the institute/study center caters the practical related demands of the learners adequately. $80 \%$ counsellors did not favour the view that special training is required for consellors for improving their capacities and skills in order to guide ODL learners in their practical activities whereas $20 \%$ counsellors favoured that special training is required for consellors for improving their capacities and skills in order to guide ODL learners in their practical activities. All the counsellors are agreed on the point that center/study center does not provide special arrangement of practical activities (other than normal practical session) for the learners who couldn't /don't attain the normal practical sessions. Further, all the counsellors are agreed on the point that they feel comfort to guide ODL learners in their practical activities.

Perception of the counsellors regarding existing problems of implementing practical based courses

$60 \%$ counsellors don't encounter any major problem while guide the ODL learners for their practical activities whereas all other counsellors encounter major problems while guide the ODL learners for their practical activities in one way or other which are cited here: $25 \%$ counsellors found that learners are irregular in attending practical; $15 \%$ counsellors found that learners are very less aware about the theory part of the practical; $15 \%$ counsellors found that there is lack of well-equipped laboratory for the ODL learners; $10 \%$ counsellors encountered that no scope is there for repeat/practice of the practical activities/experiments; and $10 \%$ counsellors found that the timing allotted for doing practical is very short.

Suggestions of the counsellors regarding effective implementing of practical based courses $35 \%$ counsellors gave no suggestion regarding effective implementing of practical based courses under ODL system whereas all other counsellors gave suggestion regarding effective implementing of practical based courses under ODL system in one way or other which are cited here: $20 \%$ counsellors suggested that theory part of the practical should be taught properly before doing practical; $\mathbf{1 5 \%}$ counsellors suggested that special practical arrangement may be done for them who are employed learners; $15 \%$ counsellors suggested that well equipped laboratory should be provided for ODL learners; $15 \%$ counsellors suggested that sufficient number of practical classes should be allotted in time table; and $10 \%$ counsellors suggested that lab technicians and counsellors should be well trained about ODL system.

\section{JUXTAPOSITION OF THE FINDINGS}

Present study is a significant attempt to study the issues in the context/area of implementing practical based courses under open and distance learning system. Present study studied the perception of the learners in implementing practical based courses under open and distance learning system; and the perception of the councellors in implementing practical based courses under open and distance learning system. Many other studies are also carried out by the other researchers relating to the present study area. The results of those studies in one way or other juxtaposed with the findings of the present study. The 
thematic juxtaposition of the results of the present study with the results of the other studies conducted in the present study area is given in the following paragraphs.

The results of the studies of Salam-Abdel, Kauffmann and Crossman (2007); Khare, Saxena and Garg (2003); Fernando (1991); and Rao and Srinivasacharyulu (1996) are different from the results of the present study in different ways as given here. From the perception of the majority of the learners of the present study it is found that practical based courses under open and distance learning system bear inferior status in comparison to practical based courses under conventional college/institutes. Salam-Abdel, Kauffmann and Crossman (2007) found no so much difference in the performance of both on-campus and distance students in writing of laboratory reports and in scoring on final examinations. Further, they found that the lack of hands on experience did not negatively affect the performance of distance students, and performance on final result is primarily dependent on individual students, regardless of whether they were on campus or learning at a distance. In the present study the majority of the learners perceived that $50 \%$ to $75 \%$ attendance or participation of students is secured in practical sessions of the practical based courses. In the study of Khare, Saxena and Garg (2003) it is found that among IGNOU science graduates about $37 \%$ students are active and only one fourth of them attempted lab courses; and Chemistry is the most popular and highest scoring subject among all the disciplines offered by IGNOU. The majority of the learners of the present study perceived that the practical works of the practical based courses are conducted in study center /substudy center only; all the components of the practical (both sessional and term end practical) of the practical based courses are conducted properly and in time; and sessional practical of the practical based courses is conducted in specific times of the session. Fernando (1991) found in the study entitled 'Conduct of Chemistry practicals in the B.Sc. degree program in the Open University of Sri Lanka' that laboratory classes are held in one long session or in a few short sessions, and the University of Sri Lanka has laboratories in the main campus for all or most of the subjects it offers. From the perception of the twofifth $(40 \%)$ of the counsellors of the present study it is found that practical laboratories/workshops for practical based courses under ODL system are moderately equipped with practical materials and equipment. Rao and Srinivasacharyulu (1996) in their study on 'Science through Distance Education: Counsellors' Response-A study' report that students come to the study centers mostly for the practicals and counseling; and the laboratory manuals-cum-record produced by the university were rated as good $(84 \%)$ by the samples.

The results of the studies of Khan (1991); Yadav, Baziruwiha and Hakizimana (2006); Khare, Saxena and Garg (2004); Rao (1996); Fox (1995); Rao and Srinivasacharyulu (1996); Kulandiswamy (1995); and Haugan (1995) are intimately corroborated with the results of the present study. The majority of the learners of the present study perceive that practical based courses under open and distance learning system bear inferior status in comparison to practical based courses under conventional college/institutes. The majority of the counsellors of the present study perceive that if practical based courses would be introduced under ODL system, they would be moderately successful. Khan (1991) conducted a study on 'Effectiveness of distance education program with reference to the teachers training course of Kashmir University'; and from the study it is found that the teaching competency of teachers trained through the formal system is higher than that of those trained through the DDE. The present study states that the problems encountered by the learners of practical based courses under ODL system while doing their practical are: problems of the adjustment of time; fail to understand the practical classes properly; no residential facility in the study center; practical classes are done superficially; communication problem to the study center; large number of students do practical at a time; and problem to understand the language used in the practical class. The present study further states that the problems that the counsellors encounter while they guide the learners of practical based courses under ODL system for their practical activities are: learners are irregular in attending practical; learners are very less aware about the theory part of the practical; there is lack of well-equipped laboratory for the ODL learners; no scope is there for repeat/practice of the practical activities/experiments; and the timing 
allotted for doing practical is very short. Yadav, Baziruwiha and Hakizimana (2006) remarked that most of the teachers have heavy workload and did not get time to work for distance learners; learners also did not get enough time for their study due to various constraints; there is shortage of science apparatus and books in the library; and there is need of enough experienced and qualified staff in distance education. Khare, Saxena and Garg (2004) in their study found that a significant group of students failed to cope with self-study in B.Sc. program. The study of Rao (1996) on 'Laboratory Training: The experience at Dr. B.R. Ambedkar Open University' reveals that there are various problems in the way of conducting practical through distance mode which are mainly: the counselors have to face heterogeneous class of students with varying academic standards, time constraints, employed persons find difficulty in getting leave, dependence on the laboratories of other institutions etc. The study of Fox (1995) on 'Teaching practical work at a distance: an evaluation study of an Open University home experiment kit' intended to study the role of Home Experiment Kit (HEK) in to carry out practical and experimental work of the practical based courses, and the result of the study reveals that - the kit itself is bulky and many students have problems finding space to set up and carry out HEK practical and experimental work; most of the students completed some of the HEK activities, while few intend to complete all and others completed only the tutor marked assessment(TMA). The present study states that regarding effective implementing of practical based courses under ODL system the suggestions given by the learners are: timing of the practical should be designed according to the needs of the learners; home based practical should be conducted; the study center should have its own practical instruments and laboratory; practical should be conducted in small groups; practical should be conducted during the holiday time; and E-based practical should be encouraged. The present study further states that regarding effective implementing of practical based courses under ODL system the suggestions given by the counsellors are: theory part of the practical should be taught properly before doing practical; special practical arrangement may be done for them who are employed learners; well-equipped laboratory should be provided for ODL learners; sufficient number of practical classes should be allotted in time table; and lab technicians and counselors should be well trained about ODL system. In Rao and Srinivasacharyulu's (1996) study, $57 \%$ of the counselors viewed that the single practical session should be split into two convenient halves. The research of Kulandiswamy (1995) on 'Technical and Vocational Programs through Distance Education' reveals that the problems of practical work can be reduced by taking some measures like- laboratory practices can be minimized or maximized based on the admission qualification; a substantial part of the laboratory classes can be fulfilled by well-prepared video-films; where appropriate the universities build kits for experiments; build laboratories in the campus and in case of students spread over wide areas laboratory classes can be arranged in a number of locations. The study of Haugan (1995) on 'Teaching science for technology at secondary level: a video-based approach in distance education' reveals that- it was both economically and pedagogically justified to apply video-recordings from ordinary lectures as substitutes for the live lectures.

\section{CONCLUSIONS AND RECOMMENDATIONS}

Implementing practical based courses under open and distance learning system is the need of the hour. Active steps should be taken from different fronts to eradicate the existing hindrances which affect in implementing and facilitating practical based courses under open and distance learning system. The under mentioned steps would be quite helpful in implementing practical based courses under open and distance learning system:

$>$ The practical based courses under open and distance learning system needs qualitative change which in turn would lead to enhancement of their status in comparison to the practical based courses under conventional colleges/institutes. Therefore, the different aspects of practical based courses under open and distance learning system starting from their admission procedure, counselling procedure, and provision of infrastructure facility etc. to 
till evaluation/certification procedure need to be changed from qualitative perspective.

$>$ More and more number of practical based courses should be opened in open and distance learning institutes with due care.

$>$ The existing gap between the theory based courses and practical based courses in open and distance learning institutes should be reduced by providing necessary infrastructure, financial support, multimedia and other such facilities etc. for the practical based courses in open and distance learning Institute.

$>$ Steps should be taken to run both long term and short term practical based courses in open and distance learning institutes/centers successfully.

$>$ Due care must be taken to modify the existing practical based courses under open and distance learning system in such a way that there would be proper balance between their theory components and practical components.

$>$ Both theory and practical components of practical based courses should be equally emphasized in open and distance learning institutes while running practical based courses.

$>$ Due care must be taken to modify the existing practical components of practical based courses under open and distance learning system in such a way that there would be proper balance between their sessional practical and term end practical.

$>$ Due care must be taken to conduct the sessional practical of practical based courses in specific times of the session so that it would become quite helpful for the learners, counsellors etc. to participate in sessional practical in a guided/effective manner.

$>$ Steps should be taken to enhance the use of multimedia in practical activities in practical based courses under open and distance learning system.

$>$ Initiation should be taken to enhance the existing level of attendance/ participation of students in practical sessions of practical based courses under open and distance learning system.

$>$ Steps should be taken to increase the different types of practical related things like practical kits, practical instruments, practical books, etc. in practical laboratory/workshops under open and distance learning system for smooth conducting of practical activities for practical based courses.

$>$ The teachers, laboratory attendants/technicians etc. working under open and distance learning system to guide the learners in their practical should be properly trained/guided about open and distance learning system so that they can handle the practical of the practical based courses under open and distance learning system.

$>$ The fees charged for pursuing practical based courses in open and distance learning system should not be too high.

$>$ Steps should be taken to arrange for conducting practical in study center /substudy centers besides the regional center / main center of the open and distance learning institution.

$>$ In some cases (or difficult areas of study) special experts/resource persons should be engaged in guiding the learners in their practical activities of practical based courses under open and distance learning system.

$>$ Open and distance learning institutes/centers would arrange special practical sessions (other than normal routine of practical work) for the learners who couldn't /don't attain the normal practical sessions because of some genuine problems.

$>$ Timing of the practical under open and distance learning system would be arranged taking into care the needs and problem of the learners.

$>$ Open and distance learning authorities may take steps to introduce home based practical works as the part of the practical of their practical based courses.

$>$ Proper care must be taken to remove all the hindrances which directly or indirectly affect the student involvement and progress in practical activities of practical based courses in open and distance learning institutes/centers. 
> Practical based courses at different levels of study like certificate level of study, diploma level of study, degree level of study etc. in open and distance learning institutes should be opened / implemented.

$>$ Steps must be taken to popularize the implementation of different types of practical based courses in open and distance learning mode, and due care must be taken for policy planning of distance education system in this regard.

\section{BIODATA and CONTACT ADDRESSES of AUTHOR}

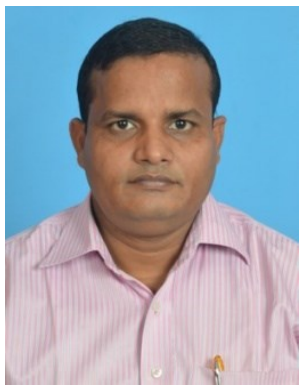

Tapan Kumar BASANTIA is an Associate Professor in School of Education, Central University of South Bihar, Gaya, Bihar, India. Formerly he was an Assistant Professor in Department of Education, Assam University(Central University), Silchar, Assam, India, and Lecturer in Department of Education, Mizoram University(Central University), Aizawl, Mizoram, India. He has wide experience in teaching Research Methodology and Statistics, Cognitive Science, Psychology of Teachinglearning, Curriculum, Pedagogy of Teaching-learning, and Educational Technology to Post Graduate and Under Graduate students of different Universities. He obtained his PhD (Education), M. Phil.(Education), M.A. (Education), M.A. (Distance Education) and M.A. (History) including Two Years Bacholor of Education Degrees from different Universities with Distinctions. He has more than a dozen of papers published in reputed and indexed journals. His main areas of work and interest are: Elementary Education, Curriculum and Pedagogy, Creativity and Education, Methodology of Educational Research and Distance Education.

\section{Tapan Kumar BASANTIA}

Associate Professor

School of Education, Central University of South Bihar

Vinoba Nagar, Magadh Colony, Gaya-823001, Bihar, India.

Phone: +91 9435724964

E-mail: tkbasantia@gmail.com

\section{REFERENCES}

Agarwal, S.R., Sharma, K.K., \& Ghosh, C.K. (2007). Best practices in Learner Support Services: A case study of IGNOU Regional Centers. Indian Journal of Open Learning, 16 (1).

Damayanti, D. (1996). Strategies in Preparing Open University Learners for Science Programs. Indian Journal of Open Learning, 5(1).

Fernando, J.N.O. (1991). Conduct of Chemistry Practicals in the B.Sc. degree program in the Open University of Sri Lanka. Proceedings of the fourth annual conference of the Asian Association of Open Universities, Colombo, Sri Lanka.

Fox, R. (1995).Teaching practical work at a distance: An evaluation study of an Open University home experiment kit. In D. Sewart (Ed.), One World Many Voices Quality in Open and distance learning, Vol.-I. U.K.: ICDEOU.

Hampton, C. (2002). Teaching Practical skills. In A.K.Mishra \& J.BartramIn (Eds.), Perspectives on Distance Education: Skills Development Through Distance Education. Vancour, Canada: Commonwealth of Learning. Retrieved from http://www.col.org/ SiteCollectionDocuments/Skills_Chapter09.pdf

Haugan, J. (1995). Teaching science for technology at secondary level: A video-based approach in distance education. In D. Sewart (Ed.), One World Many Voices; Quality in Open and distance learning, Vol.-I. U.K.: ICDEOU.

Jung, I., \& Latchem, C. (2007). Assuring Quality in Asian Open and distance learning. Open Learning, 22, 235-250. 
Khan, N. (1991). Effectiveness of distance education program with reference to the teachers training course of Kashmir University. In I. Khan (Ed.), Distance Education: Some Readings. Delhi : Amar Prakashan.

Khare, P., Saxena, A., \& Garg, S. (2004). Performance analysis of IGNOU science students in theory courses through data mining, Indian Journal of Open Learning, 13(1).

Khare,P., Saxena, A., \& Garg, S. (2003). Knowledge discoveries on performance of IGNOU science graduates through data mining. Indian Journal of Open Learning, 12 (1).

Koul, P. (2005). Counseling in Distance Nursing Education- Perception of Learners, Counselors and Program In charges. Indian Journal of Open Learning, 14(2).

Kulandiswamy, V.C. (1995). Technical and Vocational Programs through Distance Education. In Singh, B. (Ed.), New horizons in Distance Education. New Delhi: Uppal Publishing.

Nigam, A. \& Joshi, V. (2007). Science Education through Open and distance learning at Higher Education Level. Turkish Online Journal of Distance Education, 8 (4).

Rao, M.S., \& Srinivasacharyulu, G. (1996). Science through Distance Education: Counsellors' Response-A study. In M.S. Rao (Ed.), Synergy Facets of Research in Open Learning. Hyderabad, A.P.: BRAOU.

Rao, S.(1996). Laboratory Training: The experience at Dr. B.R. Ambedkar Open University. In M.S. Rao (Ed.), Synergy Facets of Research in Open Learning. Hyderabad, A.P.: BRAOU.

Salam-Abdel, T.M., Kauffmann, P.J., \& Crossman, G.R. (2007). Are distance laboratories effective tools for technology education? The American Journal of Distance Education, 21(2).

Soni, P. (2008). STRIDE-Growth and Philosophy of Distance Education; Socio-academic Issues. New Delhi: IGNOU.

Srivastava, M. (2006). IGNOU Graduates: How Did They Benefit? Indian Journal of Open Learning, 15 (3).

Yadav, L.L., Baziruwiha, J.D., \& Hakizimana,T. (2006). Science Teaching and Learning through distance training program: The Rwandan Experience. In S. Garg, $\mathbf{S}$. Panda, C.R.K. Murthy and S. Mishra (Eds.), Open and Distance Education in Global Environment. New Delhi: Viva Books Pvt. Ltd. 